\title{
AFS/FEF Student Technology Contest and Digital Poster Session
}

\section{Call for Submissions: 2016 AFS/FEF Student Technology Scholarship Contest}

\section{New Scholarships Available}

Submissions are open for the 2016 Foundry Educational Foundation (FEF) and American Foundry Society (AFS) Student Technology Scholarship Contest. The purpose of the competition is to encourage student participation and recognize excellence in student research in the field of metalcasting technology. The projects must represent current or recent work by the student(s) in the area of metalcasting technology or molten metal processing. This is intended to highlight undergraduate projects, research and other work. The contest is open only to undergraduates. The submissions will be judged prior to CASTEXPO'16. Submissions will be judged for technical merit and quality by a panel of metalcasting experts. One winning project will be selected. First Place will receive a $\$ 3,000.00$ FEF scholarship. All submissions will automatically be placed in the running for additional scholarships offered by the AFS Technical Divisions. Top submissions will be invited to attend CASTEXPO'16 from April 16-17, 2016 to display their work and participate in Q\&A sessions. Top submissions will also be published in the AFS International Journal of Metalcasting.

\section{Qualifications}

AFS/FEF Student Technology Scholarship Contest is open to North American citizens currently enrolled in metalcasting related programs at FEF certified and affiliated schools. Students must be registered with FEF and enrolled in current academic year.

\section{Submission Requirements}

Application Form-A completed application form, including the authors' signature, address, telephone number and e-mail address is mandatory. If a project is being submitted by a group, and all authors in said group project are participating in the contest, then all authors' signatures, addresses, telephone numbers and e-mail addresses are required.

Project Submission-All submissions must be submitted electronically by e-mail or through the AFS upload site. Completed application forms and final submissions must be submitted to AFS Technical Services by March 20, 2016.

Submission Guidelines-Participants must submit a digital poster using Microsoft PowerPoint 2010 or later. A template is available to act as a creation guide. Posters may include videos, infographics and other media. The projects must represent current or recent work by the student(s) in the area of metalcasting technology or molten metal processing.

Contact: Katie Matticks, AFS Library \& Technical

Services,

kmatticks@afsinc.org, $847 / 537-4237$ x 294

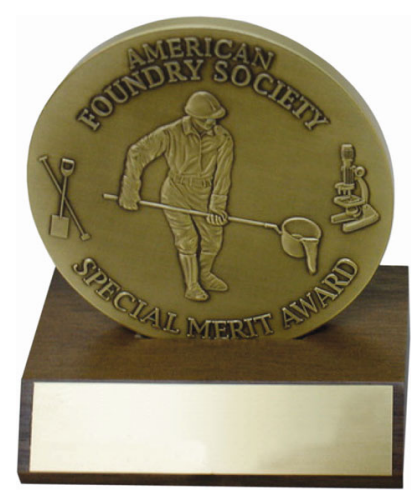

